\title{
Abnormal promoter methylation of multiple tumor suppressor genes in human bronchial epithelial malignant cells
}

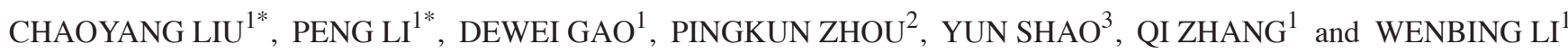 \\ ${ }^{1}$ Surgical Intensive Care Unit, Clinical Division of South Building, PLA General Hospital, Beijing 100853; \\ ${ }^{2}$ Department of Radiation Toxicology, Beijing Institute of Radiation Medicine, Beijing 100850; \\ ${ }^{3}$ Department of Pathology, Affiliated Hospital of Academy of Military Medical Sciences,
} Beijing 100071, P.R. China

Received February 27, 2014; Accepted March 27, 2014

DOI: $10.3892 /$ br.2014.268

\begin{abstract}
Carcinoma of the lung is the leading cause of cancer-related mortality worldwide. In order to understand the pathogenesis of radiation-induced lung cancer, we adopted a model of transformed human bronchial epithelial cells (BEP2D) induced by $\alpha$-particles. Methylation-specific polymerase chain reaction was performed to detect aberrant promoter methylation of multiple tumor suppressor genes, including p14 ${ }^{\mathrm{ARF}}, \mathrm{p} 16^{\mathrm{INK} 4 \mathrm{a}}, \mathrm{O}^{6}$-methylguanine-DNA methyltransferase, glutathione S-transferase P1 and death-associated protein kinase genes in the BEP2D cell line and its malignant transformant, the BERP35T1 cell line. Our results demonstrated the distinctive methylation pattern for these tumor suppressor genes in radiation-induced malignant cells, as compared to their wild-type counterparts. Our study revealed epigenetic signatures for the characterization of radiation-mediated carcinogenesis and it may facilitate early diagnosis of patients at high risk for lung cancer.
\end{abstract}

\section{Introduction}

Lung cancer is the most common cause of cancer-related mortality worldwide. A number of theories and multiple causes for lung cancer development have been proposed and it was suggested that multiple genetic modifications and signaling pathway alterations may be involved in lung oncogenesis (1). Rapid advances in this field have lead to targeted therapy, including the FDA-approved epidermal growth factor receptor and vascular endothelial growth factor inhibitors erlotinib (2) and bevacizumab (3), which have significantly improved the

Correspondence to: Dr Dewei Gao, Surgical Intensive Care Unit, Clinical Division of South Building, PLA General Hospital, 28 Fuxing Road, Haidian District, Beijing 100853, P.R. China E-mail:dwgao2@gmail.com

*Contributed equally

Key words: lung cancer, carcinogenesis, DNA methylation, tumor suppressor genes outcome in patients with non-small-cell lung cancer. The identification of additional molecular markers specific to lung cancer may improve early detection, which is critical for improving survival.

A major role for epigenetic mechanisms has been suggested in cancer development (4). Specifically, methylation patterns are significantly altered in cancer cells. Hypermethylation of certain $\mathrm{CpG}$ islands is observed in the majority of tumor cells and is associated with gene silencing. This is more prominent for certain tumor suppressor genes whose loss-of-function promotes carcinogenesis (5). The DNA methylation status may also provide a highly sensitive and specific marker for early cancer diagnosis.

To investigate the pathogenesis of radiation-induced lung cancer and further provide evidence for clinical application, we established a model of transformed human bronchial epithelial cells (BEP2D) induced by $\alpha$-particles (6) and the methylation status in the promoter regions of multiple tumor suppressor genes was analyzed by methylation-specific polymerase chain reaction $(\mathrm{PCR})$.

\section{Materials and methods}

Cell culture. The BEP2D cell line is a human papillomavirus 18-immortalized human bronchial epithelial cell line and was kindly provided by Dr Curtis C. Harris (National Cancer Institute, MD, USA) (7). The BERP35T1 malignant transformant cell line was derived from the BEP2D cell line through $\alpha$-particle irradiation (6). The cells were cultured in serum-free LHC- 8 medium (Biofluids Inc., Rockville, MD, USA) at $37^{\circ} \mathrm{C}$ under a $95 \%$ air $/ 5 \% \mathrm{CO}_{2}$ atmosphere.

SssI methyltransferase treatment. Genomic DNA was extracted from normal lung tissue and treated with SssI methyltransferase (New England Biolabs, Ipswich, MA, USA). SssI-treated DNA was then used as a substrate for methylation-specific PCR.

Methylation-specific PCR analysis. We extracted and purified genomic DNA from BEP2D cells and their malignant transformants, BERP35T1 cells. Following modification by treatment with sodium bisulfite, methylation-specific PCR (8) 
Table I. Primers used for methylation-specific polymerase chain reaction.

\begin{tabular}{|c|c|c|c|c|}
\hline Gene & Sense primer $\left(5^{\prime}-3^{\prime}\right)$ & Antisense primer (5'-3') & $\begin{array}{l}\text { Annealing } \\
\text { temp }\left({ }^{\circ} \mathrm{C}\right)\end{array}$ & $\begin{array}{l}\text { Size } \\
\text { (bp) }\end{array}$ \\
\hline \multirow[t]{2}{*}{$\mathrm{p} 16^{\mathrm{INK} 4 \mathrm{a}}$} & M: TTATTAGAGGGTGGGGCGGATCGC & M: GACCCCGAACCGCGACCGTAA & 65 & 150 \\
\hline & U: TTATTAGAGGGTGGGGTGGATTGT & U: CAACCCCAAACCACAACCATAA & 65 & 151 \\
\hline \multirow[t]{2}{*}{ MGMT } & M: TTTCGACGTTCGTAGGTTTTCGC & M: GCACTCTTCCGAAAACGAAACG & 66 & 81 \\
\hline & U: TTTGTGTTTTGATGTTTGTAGGTTTTTGT & U: АACTCCACACTCTTCCAAAAACAAAACA & 66 & 93 \\
\hline \multirow[t]{2}{*}{ DAPK } & M: GGATAGTCGGATCGAGTTAACGTC & M: CCCTCCCAAACGCCGA & 64 & 98 \\
\hline & U: GGAGGATAGTTGGATTGAGTTAATGTT & U: CAAATCCСТCССАAАCACCAA & 64 & 106 \\
\hline \multirow[t]{2}{*}{$\mathrm{p} 14^{\mathrm{ARF}}$} & M: GTGTTAAAGGGCGGCGTAGC & M: AAAACCCTCACTCGCGACGA & 64 & 122 \\
\hline & U: TTTTTGGTGTTAAAGGGTGGTGTAGT & U: CACAAAAACCCTCACTCACAACAA & 64 & 132 \\
\hline \multirow[t]{2}{*}{ GSTP1 } & M: TTCGGGGTGTAGCGGTCGTC & M: GCCCCAATACTAAATCACGACG & 55 & 91 \\
\hline & U: GATGTTTGGGGTGTAGTGGTTGTT & U: CСАССССААТАСТАААТСАСААСА & 55 & 97 \\
\hline
\end{tabular}

M, methylation-specific primer; U, unmethylation-specific primer; MGMT, $\mathrm{O}^{6}$-methylguanine-DNA methyltransferase; DAPK, death-associated protein kinase; GSTP1, glutathione S-transferase P1.

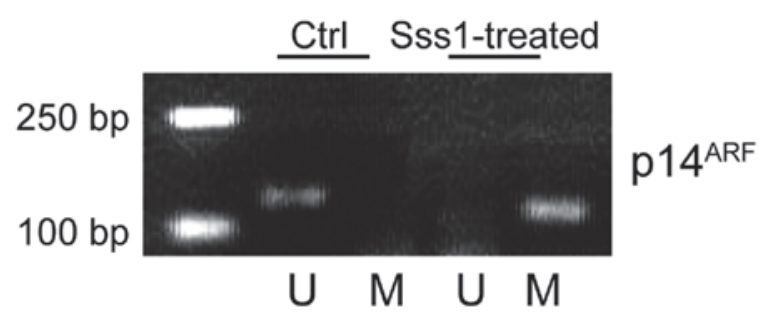

Figure 1. Methylation-specific polymerase chain reaction (PCR). Genomic DNA was extracted from normal lung tissue and DNA samples with or without Sss1 methyltransferase treatment were then used as substrates in methylation-specific PCR. U, lane for unmethylated PCR product; M, lane for methylated PCR product.

was performed with $2 \mu \mathrm{l}$ of bisulfite-treated DNA with methylation- and unmethylation-specific primers for each tumor suppressor gene. The amplified products were separated electrophoretically on 3\% agarose gels and visualized using ethidium bromide staining. The primer sets and size of the amplified products are listed in Table I.

\section{Results}

Verification of methylation detection system. The analyses of the methylation status of the genes were performed by methylation-specific PCR. For the purpose of verification of our methylation detection system, we extracted DNA from normal lung tissue and then treated it with SssI methylase. SssI methylase-treated and unmodified DNAs were used as substrates for the PCR reaction using $\mathrm{p} 14^{\mathrm{ARF}}$ gene methylation-specific PCR primers. As shown in Fig. 1, a positive PCR product appeared in the SssI methylase-treated DNA sample, but not in the untreated control group, reflecting the specificity of our detection system. The results were further confirmed by direct DNA sequencing.

Methylation-specific PCR of tumor suppressor genes. In view of the critical role played by tumor suppressors in cell cycle
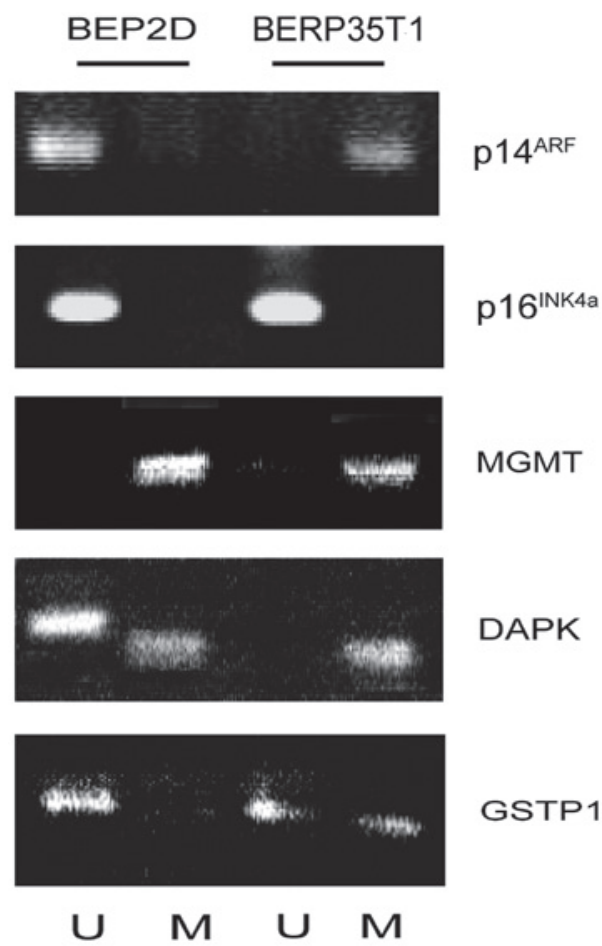

Figure 2. Methylation-specific polymerase chain reaction (PCR) showing the methylated and unmethylated PCR products for multiple tumor suppressor genes, including $\mathrm{p} 14^{\mathrm{ARF}}, \mathrm{p} 16^{\mathrm{INK} 4 \mathrm{a}}, \mathrm{O}^{6}$-methylguanine-DNA methyltransferase (MGMT), death-associated protein kinase (DAPK) and glutathione S-transferase P1 (GSTP1) genes in the transformed human bronchial epithelial cell line (BEP2D) and its malignant transformant (BERP35T1). U, lane for unmethylated PCR product; M, lane for methylated PCR product.

control and tumor genesis, we investigated the methylation status of multiple tumor suppressor genes in BEP2D cells and their malignant transformant BERP35T1 cells induced by $\alpha$-particles. The $\mathrm{CpG}$ island in the $5^{\prime}$ promoter region of the p14 ${ }^{\mathrm{ARF}}$ gene was unmethylated in BEP2D cells, but was modified through methylation in the malignant transformant BERP35T1 cells. Of note, the p16 ${ }^{\text {INK4a }}$ gene, which shares two 
exons with the p14 ${ }^{\mathrm{ARF}}$ gene, was not methylated in the promoter CpG islands.

The $\mathrm{O}^{6}$-methylguanine-DNA methyltransferase (MGMT) gene is a specific DNA repair enzyme, which removes the alkyl group from the $\mathrm{O}^{6}$-position of guanine, preventing its mutagenic and carcinogenic effects $(9,10)$. The MGMT gene was found to be methylated in BEP2D cells, as well as in malignant transformant BERP35T1 cells (Fig. 2).

Death-associated protein kinase (DAPK) is a multi-domain serine/threonine protein kinase that possesses apoptotic and tumor-suppressive functions (11). The DAPK gene was partially methylated in BEP2D cells and completely methylated in BERP35T1 cells (Fig. 2).

Methylation of the glutathione S-transferase P1 (GSTP1) gene promoter region is the most common epigenetic change in prostate cancer (12). The GSTP1 gene was unmethylated in BEP2D cells and partially methylated in BERP35T1 cells, suggesting that it may also involved in lung oncogenesis (Fig. 2).

\section{Discussion}

DNA methylation in the promoter region is an important mechanism of tumor suppressor gene inactivation in human cancers. An alteration in the methylation status, particularly hypermethylation, typically occurs at $\mathrm{CpG}$ islands in the promoter region and is associated with tumor suppressor gene inactivation, ultimately leading to carcinogenesis $(13,14)$.

We used the $\alpha$-particle-induced malignant transformant BERP35T1 cell line as a cell culture model for lung carcinogenesis; this cell line was derived from the BEP2D cell line, a human papillomavirus 18 -immortalized human bronchial epithelial cell line (7). Ionizing radiation was selected to establish BERP35T1, as it may induce a high incidence of large chromosomal deletions or translocations as a result of strand breakage (15). When compared to BEP2D cells, malignant transformant BERP35T1 cells exhibited altered growth kinetics, resistance to serum-induced terminal differentiation and anchorage-independent growth.

To elucidate the molecular mechanism underlying radiation-mediated carcinogenesis, we used methylation-specific PCR to detect aberrant promoter methylation of multiple tumor suppressor genes, including $\mathrm{p} 14^{\mathrm{ARF}}$ and $\mathrm{p} 16^{\mathrm{INK} 4 \mathrm{a}}$ (cell cycle regulators), MGMT and GSTP1 (DNA repair) and DAPK (cell apoptosis) genes in BEP2D cells and malignant transformant BERP35T1 cells. As shown in Fig. 2, these genes exhibited different methylation patterns. For example, p16 ${ }^{\mathrm{INK} 4 \mathrm{~A}}$ and $\mathrm{p} 14^{\mathrm{ARF}}$ are two tumor suppressors encoded by the cyclin-dependent kinase inhibitor $2 \mathrm{~A}$ gene locus. Through alternative splicing, $\mathrm{p} 16^{\mathrm{INK} 4 \mathrm{~A}}$ and $\mathrm{p} 14^{\mathrm{ARF}}$ have distinct promoter regions and first exons, but share the second and third exons. The $\mathrm{p} 16^{\mathrm{INK} 4 \mathrm{~A}}$ and $\mathrm{p} 14^{\mathrm{ARF}}$ proteins have important functions in cell cycle regulation and generally act as negative regulators of cell cycle progression. p16 ${ }^{\mathrm{INK} 4 \mathrm{~A}}$ mainly acts via the retinoblastoma pathway as an inhibitor of the cyclin-dependent kinases 4 and 6 (16) and p14 ${ }^{\mathrm{ARF}}$ is crucial for the p53 pathway through inhibiting mouse double minute 2 homolog $(17,18)$. Our findings demonstrated that the methylation status of p16 ${ }^{\mathrm{INK} 4 \mathrm{~A}}$ and $\mathrm{p} 14^{\mathrm{ARF}}$ was regulated in a distinctive pattern, suggesting that $\mathrm{p} 16^{\mathrm{INK} 4 \mathrm{~A}}$ and $\mathrm{p} 14^{\mathrm{ARF}}$ are separately involved in tumor development.
Our results also demonstrated a distinctive methylation pattern among other tumor suppressors in $\alpha$-particle-induced malignant transformant BERP35T1 cells, when compared to their wild-type counterparts. For example, the MGMT gene was methylated in both cell lines; the DAPK gene was only partially methylated in wild-type cells and completely modified through methylation in the malignant transformed cell line; as regards the GSTP1 gene, it was unmethylated in wild-type cells and partially methylated in BERP35T1 cells.

Our final goal is to apply DNA methylation markers in early lung cancer diagnosis. Achieving this goal largely depends on the sensitivity and specificity of these epigenetic markers. Our present study demonstrated the practicality of this approach, since the methylation patterns are quite distinctive for the malignant transformed cell line compared to its wild-type counterpart. Our ongoing efforts are aimed at screening high-risk groups for lung cancer using these epigenetic signature and suggest a future direction for manipulating epigenetic alterations towards lung cancer therapy.

\section{Acknowledgements}

This study was supported by a grant from the National High Technology Research and Development Program of China (863 Program) (no. 2001AA221271), a grant from the Major State Basic Research Development Program of China (973 Program) (no. G1998051207), a grant from the Military Scientific Research Foundation for Returned Scholars (no. 98H037) and a grant from the Military Science Foundation for The Excellent Youth Scholars during the 9th Five-Year Plan Period (no. 01J006).

\section{References}

1. Herbst RS, Heymach JV and Lippman SM: Lung cancer. N Engl J Med 359: 1367-1380, 2008.

2. Shepherd FA, Rodrigues Pereira J, Ciuleanu T, et al: Erlotinib in previously treated non-small-cell lung cancer. N Engl J Med 353: 123-132, 2005.

3. Sandler A, Gray R, Perry MC, et al: Paclitaxel-carboplatin alone or with bevacizumab for non-small-cell lung cancer. N Engl J Med 355: 2542-2550, 2006.

4. Boehm JS and Hahn WC: Towards systematic functional characterization of cancer genomes. Nat Rev Genet 12: 487-498, 2011.

5. Esteller M: $\mathrm{CpG}$ island hypermethylation and tumor suppressor genes: a booming present, a brighter future. Oncogene 21: 5427-5440, 2002.

6. Lou T, Xiang X and Wu D: Transformation of human bronchial epithelial cells BEP2D induced by ${ }^{238} \mathrm{Pu} \alpha$-particles. Chin J Lung Canc 3: 428-431, 2000 (In Chinese).

7. Willey JC, Broussoud A, Sleemi A, et al: Immortalization of normal human bronchial epithelial cells by human papillomaviruses 16 or 18. Cancer Res 51: 5370-5377, 1991.

8. Herman JG, Graff JR, Myohanen S, Nelkin BD and Baylin SB: Methylation-specific PCR: a novel PCR assay for methylation status of CpG islands. Proc Natl Acad Sci USA 93: 9821-9826, 1996.

9. Esteller M, Hamilton SR, Burger PC, Baylin SB and Herman JG: Inactivation of the DNA repair gene $\mathrm{O}^{6}$-methylguanine-DNA methyltransferase by promoter hypermethylation is a common event in primary human neoplasia. Cancer Res 59: 793-797, 1999.

10. Wolf P, Hu YC, Doffek K, Sidransky D and Ahrendt SA: $\mathrm{O}^{6}$-Methylguanine-DNA methyltransferase promoter hypermethylation shifts the p53 mutational spectrum in non-small cell lung cancer. Cancer Res 61: 8113-8117, 2001.

11. Bialik S and Kimchi A: The death-associated protein kinases: structure, function, and beyond. Annu Rev Biochem 75: 189-210, 2006. 
12. Esteller M, Corn PG, Urena JM, Gabrielson E, Baylin SB and Herman JG: Inactivation of glutathione S-transferase P1 gene by promoter hypermethylation in human neoplasia. Cancer Res 58: 4515-4518, 1998

13. Widschwendter $M$ and Jones PA: The potential prognostic, predictive, and therapeutic values of DNA methylation in cancer. Clin Cancer Res 8: 17-21, 2002.

14. Hatziapostolou M and Iliopoulos D: Epigenetic aberrations during oncogenesis. Cell Mol Life Sci 68: 1681-1702, 2011.

15. Hall EJ and Hei TK: Genomic instability and bystander effects induced by high-LET radiation. Oncogene 22: 7034-7042, 2003.
16. Kashiwabara K, Oyama T, Sano T, Fukuda T and Nakajima T: Correlation between methylation status of the p16/CDKN2 gene and the expression of $\mathrm{p} 16$ and $\mathrm{Rb}$ proteins in primary non-small cell lung cancers. Int J Cancer 79: 215-220, 1998.

17. Zhang Y, Xiong Y and Yarbrough WG: ARF promotes MDM2 degradation and stabilizes p53: ARF-INK4a locus deletion impairs both the $\mathrm{Rb}$ and $\mathrm{p} 53$ tumor suppression pathways. Cell 92: 725-734, 1998 .

18. Sherr CJ: Tumor surveillance via the ARF-p53 pathway. Genes Dev 12: 2984-2991, 1998. 